\title{
Fotografía Porfiriana: La intencionalidad y la mirada en la revista El Mundo Ilustrado
}

\author{
Porfiriana Photography: Intentionality and the look in the magazine El Mundo Ilustrado
}

\author{
Salvador Salas-Zamudio ${ }^{\text {a }}$, Ruth Yolanda Atilano-Villegas ${ }^{b}$
}

\begin{abstract}
:
During the Porfiriato (1876-1911) the photographic image acquired great popularity and importance in society, it reflected the aspirations of the members of the ruling class formed by large landowners, important industrialists, wealthy merchants, miners and bankers who sought to maintain their wealth and maintain its political and ideological control through the financing of most publications. Although freedom of expression and printing had been guaranteed in the Constitution of 1857, the Gag Act of 1882 punished subversive and immoral journalists who intended to disrupt public order, incite disobedience of laws or damage moral and moral canons social behavior. The Porfirista press legitimized the order and progress that sustained the government through a significant amount of graphic content, illustrations and photographs that showed progress and social stability. In the pages of the illustrated magazines, among which we can mention the illustrated world (1894 - 1914), the Mexican elite was reflected in written reports and in photographic images as faithful copies of reality, a photograph that as a mirror gave exact account of conservatism and social catholicism. Rafel Reyes Spíndola, owner, director and editor of the Dominican weekly newspaper El mundo illustrated, “... bought large print presses and began using both German linotypes and the halftone technique”. (De la Torre, 1998, p. 348)
\end{abstract}

Keywords:

Photography, representation, porfiriato, press, ruling class

\section{Resumen:}

Durante el Porfiriato (1876 - 1911) la imagen fotográfica adquirió gran popularidad e importancia en la sociedad, reflejó los aspiraciones de los miembros de la clase dominante conformada por grandes terratenientes aburguesados, importantes industriales, comerciantes acaudalados, mineros y banqueros que pretendían mantener sus riquezas y mantenr su control politico e ideológico mediante el financiamiento de la mayoría de las publicaciones. Aunque la libertad de expresión y de imprenta había quedado garantizada en la Constitución de 1857, la ley Mordaza de 1882 castigaba a los periodistas subversivos e inmorales que pretendieran trastornar el orden público, incitar a la desobediencia de las leyes o dañar los cánones morales y de comportamiento social.

La prensa porfirista legitimaba el orden y el progreso que sustentaba el gobierno a través de una cantidad importante de contenido gráfico, ilustraciones y fotografías que mostraban el progreso y la estabilidad social. En las páginas de las revistas ilustradas, entre las que podemos mencionar a El mundo ilustrado (1894 - 1914), la élite mexicana se vió reflejada en reportajes escritos y en imágenes fotográficas como copias fieles de la realidad, fotografías que como espejo daban cuenta exacta del conservadurismo y el catolisismo social.

Rafel Reyes Spíndola, propietario, director y editor del semanario domincal El mundo ilustrado, “... compró rotativas de gran tiraje y empezó a utiizar tanto linotipos alemanes como la técnica de medio tono”. (De la Torre, 1998, p. 348)

\section{Palabras Clave:}

Fotografía, representación, porfiriato, prensa, clase dominante

\footnotetext{
a Universidad de Guanajuato, Departamento de Artes Visuales, Email: s.salas@ugto.mx

b Universidad de Guanajuato, Centro de Estudios y Acciones para el Desarrollo Social y Humano, Email: atilanovillegas@ gmial.com
} 


\section{Introducción}

El mundo vivía lo que se ha dado en llamar la Segunda Revolución Industrial, la cual, se dejó sentir en todas las esferas de acción humana, así mismo, tomaba fuerza la nueva configuración del orden social con la burguesía a la cabeza; ese fue el marco de la invención de la fotografía, en ello descansa su origen y su razón de ser.

Dicho invento no tardó en llegar a tierras mexicanas por el puerto de Veracruz; en la corbeta francesa La Flore venían tres equipos de daguerrotipia para los comerciantes Leverger Hermanos, en ese mismo navío el grabador Jean Francois Prelier Duboille, que desde 1837 radicaba en la ciudad de México, desembarcó con dos cámaras de daguerrotipa compradas en París; el calendario contaba los tres días del mes de diciembre de 1839. A Prelier Duboille se le adjudica el primer daguerrotipo realizado en México, muestra en primer plano la iglesia del convento de San Francisco y en segundo al castillo de San Juan de Ulúa, tomado en el propio puerto de Veracruz.

Durante los primeros días del año siguiente, el 26 de febrero de 1840, en la prensa dicho descubrimiento ocuparía las páginas de El Cosmopolita con exhibición en la Plaza de Armas y la rifa de un daguerrotipo, 80 láminas de plaqué y algunos accesorios (García, 1978). Poco a poco, la fotografía fue abriéndose paso en el gusto del público, alcanzando un auge sostenido, particularmente de retrato de la burguesía y de los personajes políticos más importantes, a partir del Segundo Imperio $(1863$ - 1867) y durante el Porfiriato se le entronizó como uno de los emisarios de la modernidad, se le dio un uso como legitimadora del ejercicio de Díaz en el poder y en la práctica se constituyó en un espejo de la ideología de la burguesía.

Durante el porfiriato la fotografía de registro tuvo en lugar destacado, ya fuera para dar seguimiento a la construcción de puertos, del Ferrocarril Nacional e incluso para reconocimiento de zonas geográficas y haciendas más distantes del país. Porfirio Díaz contrató a fotógrafo extranjeros para realizar este tipo de trabajos como Abel Briquet, Charles B. Waite, W. Scott y William Henry Jackson. (Monroy, 2010)

Fue así como la fotografía reflejó los sueños de los miembros de la clase dominante (Bourdieu, 2002) durante la llamada Belle Epoque que se extendía por todo el orbe, entre los cuales resaltaba el de colocar a México entre las grandes potencias mundiales.
Ciertamente, se vivían nuevos tiempos, en un territorio y con un gobierno más estable después de tantas guerras intestinas, finalmente, parecía que todo comenzaba a tomar su lugar, Porfirio Díaz en conjunción con los científicos imbuídos en la filosofía positivista promovieron una nueva época política, económica y social a través del orden y el progreso. Lo cual se reflejó en aspectos específicos como la industria, el comercio y la banca; la construcción de vías de comunicación y multiplicación de transportes; la modernización de la traza urbana, ampliación de servicios públicos y la construcción de grandes obras cargo de arquitectos extranjeros como Adamo Boari, Emile Bernard, Maxime Roisin, Silvio Contri, Ernest Brunel o de arquitectos mexicanos como Antonio Rivas Mercado, Emilio Dondé, Manuel Ortiz Monasterio, Bernardo Calderón, Ignacio Marquina, Federico Mariscal y Jesús T. Acevedo, entre otros.

La Ciudad de México, la llamada "París de América", fue el escenario donde los recién instalados pavimento y bombillas fueron los testigos de la vida que se gestaba en medio de los paseos dominicales en parques y jardines 0 durante las compras en los grandes almacenes ubicados en las calles céntricas como Plateros, La Profesa y San Francisco; entre los pasatiempos como el teatro, las carreras de caballos, las kermeses, o el five o'clock tea; en las elegantes colonias como Arquitectos, Paseo Nuevo, Tabacalera, Cuauhtémoc y Juárez, colindantes al recién embellecido y terminado Paseo de la Reforma, una vía arbolada en la circularon los carruajes tirados por caballos, con sus grandes bancas de cantera, la estatua ecuestre de Carlos IV y, pedestales en los que se instalaron estatuas de los personajes ilustres de la Reforma. En la vida privada más allá de los muros de las hermosas casonas art nouveau, con fachadas y decoraciones interiores fitofórmicas, inspiradas en los tallos de flores, en delicados insectos como libélulas y mariposas o en los cabellos de mujer, ubicadas en las colonias Santa María la Ribera, San Rafael, Cuauhtémoc, Juárez, Roma y Condesa, o en las casas de veraneo y quintas campestres de familias adineradas, ubicadas en Tacubaya, Mixcoac y San Ángel, o los establecimientos de grandes tiendas departamentales, teatros como el Lírico, el Principal, el Colón, el Renacimiento, restaurantes con elegantes utensilios de plata de la marca Christofle, cristalería de Bohemia, porcelanas de Sajonia de marcas como Limoges y Baccarat en los que se servían platillos de faisán, chocha, pavipollo, codorniz, pichón, pato, jabalí, ciervo, gamo, corzo, bisonte, venado, chocha, liebres o conejo (Guerrero, Arredondo \& Cruz 2018). Tívolis con amplios jardines y salones para banquetes, hipódromos, clubes o salones 
del té que a semejanza de la rue de la Pax y la Place Vendome en París. ¿Quién puede olvidar a El Palacio de Hierro, al restaurante de Sylvain; al Jockey club, al Casino Español, al Tívoli del Eliseo o al Hipódomo de Peralvillo?

El redundante fortalecimiento de las ideas fundamentales que caracterizaron a la Belle epoque porfiriana distinguida por el lujo, el confort y por la civilidad sustentada en el comportamiento de la burguesía, normada por los manuales de urbanidad y por el progreso engalanado por la llegada del cinematógrafo, el automóvil, el fonógrafo, el teléfono y la fotografía.

Una ciudad de contrastes económicos y sociales donde el comercio ambulante recorría las calles céntricas y la clase popular, conformada por indígenas, campesinos, obreros y peones, saciaba su hambre con tortillas, frijol, picante y pulque. Las mujeres obreras tenían que trabajar, mientras que las institutrices -damas, finas y recatadas provenientes de familias acomodadas-, instruían a las mujeres de la élite en buenos modales, ciencias, español y matemáticas, para preservar el ideal femenino: dulce, recatada, hermosa y buena católica.

Para las mujeres porfirianas que quisieran mantener un lugar decoroso en la sociedad existían unas rigurosas pautas de comportamiento que reducían su vida y su comportamiento a los límites de su hogar. Cualquier conducta pública fuera de este código, sería determinante para su honor y el de toda su familia. La joven porfiriana, debía ser educada con esmero en la modestia, recogida, amable y graciosa, no sólo ser virtuosa, sino siempre parecerlo. Su tarea era atender el hogar, cuidar de los hijos y guardar fidelidad al marido, obligada a permanecer en la privacidad, fuera del mundo público que estaba reservado solo para los hombres... se les educaba en la costura y confección, e incluso muchas sabían leer, escribir y contar, es por esto que a pesar de su invisibilidad, se puede conocer acerca de sus vidas gracias a las publicaciones diarias o semanales que estaban dedicadas a ellas. Estas publicaciones para mujeres estaban escritas y editadas por hombres cuya labor era educarlas siguiendo el ideal ilustrado abordando distintos aspectos de la vida femenina... (MODO, 2015)

\section{Desarrollo}

La fotografía adquirió importancia sustantiva durante el Porfiriato, se comercializaron las placas secas, las cámaras y equipos más sencillos, motivando la competencia entre profesionales y favoreciendo el surgimiento de aficionados. "Al cumplirse cincuenta años de existencia de la fotografía, los usos y la recepción de las imágenes también experiementaron transformaciones importantes. Se consolidó el género del retrato y se abrieron importantes y refinados estudios fotográficos en la ciudad de México y en otros centros urbanos del interior." (Castillo, 2005, p. 59).

Se popularizó el uso de las placas secas al gelatinobromuro de plata desbancando al colodión, utilizado hasta 1880; cámaras y técnicas confluyeron para permitir la paulatina democratización de la imagen. En torno de la fotografía, también comenzaron a surgir otras manifestaciones como la Sociedad Fotográfica Mexicana, fundada por el ingeniero Fernando Ferrari Pérez en 1890 y en la que sus miembros no eran fotógrafos profesionales.

El liberalismo impulsado por la Reforma y la introducción del pensamiento ilustrado, dio paso al surgimiento de semanarios y revistas dirigidas específicamente a las mujeres, que proporcionaban consejos útiles para las labores del hogar y para ser la esposa perfecta, como Semanario de las señoritas mexicanas destinado a la educación científica, moral y literaria del bello sexo (1841), Panorama de las señoritas. Periódico pintoresco, científico y literario (1842), El Correo de las Señoras (1883-1893), El periódico de las Señoras (1896) y El Mundo Ilustrado (1900-1914). Por otro lado, había publicaciones que defendían el derecho de la mujer a la educación y las instruía en las ciencias, arte y literatura, como La mujer (1880-1883), El Álbum de la mujer (1884-1888), Álbum de Damas (1907 - 1908), Las Hijas del Anáhuac (1887-1888), Violetas del Anáhuac (1888), El Mundo (1894-1899), La Mujer Mexicana (1904 -1906), entre otras revistas ilustradas que privilegiaron el uso de la imagen en portadas, reportajes y anuncios publicitarios. "Hacia 1904, El Mundo Ilustrado, con sede en el flamante edifico construido por Antonio Rivas Mercado, se apreciaba de contar con un taller de dibujo... el taller de grabado se encargaba de la toma de negativos, el revelado, el grabado y la impresión con iluminación artifical..." (Ortiz, 2004, p. 10). 


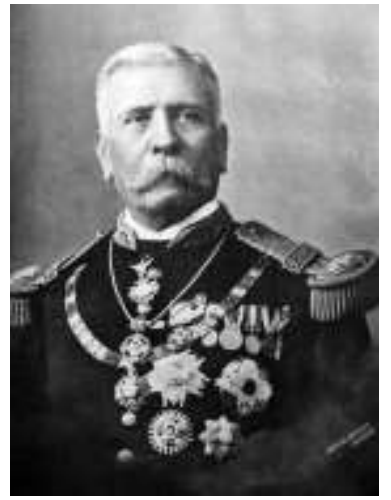

Fotografía 1. Porfirio Díaz, El mundo ilustrado, Ciudad de México, 16 de septiembre de 1900. Colección particular de María de la Cruz Labarthe Ríos. Reproducción Ruth Yolanda Atilano Villegas.

El oficio de fotógrafo se robusteció, también como un factor comercial con la consolidación y apertura de nuevos estudios fotográficos en la zona aledaña a Palacio Nacional o en la provincia mexicana como Guillermo (Wilhelm) Kahlo, Antíoco Cruces y Luis Campa, Hermanos Valleto, Manuel M. Ramos, Mack, Frank L. Clarke, Emilio Lange, Manuel y Felipe Torres, Octaviano de la Mora, Gómez Gallardo, Napoléon, Arriaga, Chávez, José María Lupercio, por mencionar algunos fotógrados que colaboraron en El mundo ilustrado y en El Semanario ilustrado; así mismo continuaron los fotógrafos viajeros captando las imágenes de la vida a su paso como Carl Lumholtz, Claude-Joseph Désiré Charnay, Teobert Maler, Alfred Percival Maudslay, el matrimonio Alice y Augustus Le Plongeon, Alfred Saint-Ange Briquet, William Henry Jackson y Agustín Víctor Casasola y Miguel Casasola relacionados con el poder propagandistico de Porfirio Díaz. También fue posible que aficionados, como por ejemplo, Juan Antonio Azurmendi, mexicano de origen vasco, retrataran la intimidad de la vida familiar (Castillo, 2005).

Además de las manifestaciones palpables en los avances científicos, tecnológicos y comerciales en el desarrollo del oficio en México, es muy importante e insoslayable hablar de la difusión de la fotografía en diversos soportes, como las tarjetas postales, los álbumes conmemorativos, las tarjetas de visita, los álbumes familiares, registros oficiales y la prensa decimonónica que resultó fundamental para la demostración y uso del nuevo invento. En dichos soportes se pueden encontrar ejemplos de los géneros fotográficos desarrollados en el siglo XIX: retrato (de desnudo, eventos sociales, de identificación, o difuntos), fotografía documental (costumbrista, de paisaje, de viajes 0 guerras) y fotografía academicista (Pictorialismo), entre otros.

Durante el Porfiriato, la prensa se consolidó también, pues antes los periódicos y revistas eran muy efímeros, lo cual estaba íntimamente relacionado con la inestabilidad política y económica de antaño, y en estricto sentido, tampoco se escapó con los avances tecnológicos y técnicos. Los propósitos de la prensa eran muy claros, en primer lugar el de mantener informada a la población y en segundo, el de constituirse como un elemento de diversión. Lo anterior, ampliamente ligado al ocio, elemento tan característico de la burguesía, en términos de Thorstein Veblen (Veblen, 2000). De esta manera, la prensa se constituía como un referente de las élites ilustradas, puesto que sólo la clase dominante, formada por la burguesía y la clase media tenía desarrollada la capacidad lectora.

Había una diversidad de periódicos y revistas; algunos de corte oficial y en contra del régimen; de corte familiar, masculino o femenino; de tiraje diario o semanal; de contenido político, económico, social, cultural, o misceláneo; de inclinación católica, anticlerical, feminista, anarquista, liberal, entre otras; de configuración temática como por ejemplo, aquellos dedicados a la moda.

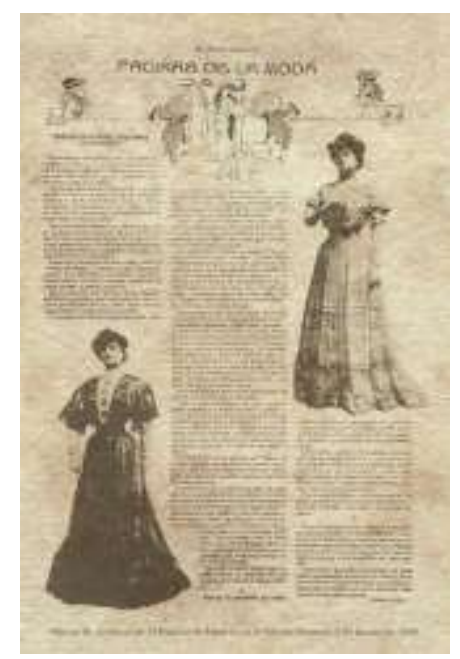

Fotografía 2. Artículo publicado el 1 de marzo de 1908 en El Mundo llustrado. (Hellion, 170). En

http://entretejidos.iconos.edu.mx/thesite/a-proposito-delporfiriato/

Entre la enorme cantidad de los periódicos editados durante el Porfiriato sobresalen en orden de importancia por la cantidad de periódicos tirados: El Imparcial, El Universal, El Tiempo, El Globo, El Nacional, y El diario 
del hogar. Y si de revistas se trata, gozaron de gran popularidad El Mundo Ilustrado, la Revista Moderna, Arte y Letras, El Tiempo llustrado y Álbum de Damas, entre otras, las cuales convivían con almanques, cuadernillos y folletería de hojas sueltas.

Las mencionadas publicaciones, fueron fabricadas con maquinaria importada y novedosas técnicas de reproducción fotomecánica, lo que hacía posible la emisión de grandes tirajes; poseía un sistema moderno de venta, implementado en en extranjero; con presencia en buena parte de la república gracias a la mejora en el servicio de correos, obra pública y los medios de transporte (s/a, 1904).

Las revistas ilustradas, como El mundo ilustrado sin duda fueron "la joya de la corona" para el régimen porfiriano, pues en ellas se mostraba el progreso y la civilidad antes aludidas con garbo, mediante un contenido muy variado relacionado con la cultura de la clase dominante y haciendo uso de los más novedosos procesos y mejores materiales de la industria editorial, tal es el caso de la adopción de las placas de fotograbado o los procesos de medio tono implementados allá por 1885 (Castillo, 2005), lo cual impactó en la producción de imágenes revolucionando la imagen misma en sus posibilidades, dando elementos a la intención, poniéndola al alcance de la mirada.

En dichas publicaciones, al principio cohabitaron en sus páginas los grabados y las fotografías; con el transcurso del tiempo, la fotografía fue dejando de lado a cualquier otra forma de hacer imágenes en la prensa decimonónica. Este sería el espacio donde se difundiría la fotografía de estudio y surgiría el oficio de los fotoreporteros. El invento atribuido a Daguerre, tuvo renombrados aprendices y maestros del oficio en tierras mexicanas: Guillermo Kahlo, los hermanos Valleto, los hermanos Torres, Manuel Ramos, Emilio Lange, Hugo Brehme, Agustín Víctor Casasola y mujeres como Natalia Baquedano, Elena y Ana Arriaga, Margarita Aguirre, María Luisa González, Gertrudis G. Cerda, Ascensión Cobos, Concepción Muñóz, y Pilar Gordon (Castillo, 2005).

Los fotógrafos, alcanzaron un reconocimiento social gracias a la calidad de su trabajo, la elegancia de sus estudios, su lista de clientes, que en su conjunto podría llamarse prestigio; algunos habían estudiado en la Academia de San Carlos. En sus estudios ubicados en las calles más céntricas y de prestigio comercial, el maestro y sus asistentes se preparaban para la toma; el fotógrafo se encargaba de supervisar todas las operaciones, de la atención a los clientes; los asistentes realizaban en trabajo de revelar, imprimir, retocar y acabar; en ellos se instalaba un decorado, se definían las temáticas fotográficas, se estudiaban las poses. (Debroise, 1985), Con ello quedaba perpetuado para la posteridad el rostro de la clase dominante y su vida burguesa, la de caballeros de bombín y damas con vestidos elegantes.

Si se habla de la prensa porfiriana es ineludible mencionar un nombre, el de Rafael Reyes Spíndola, creador del periodismo moderno en México y miembro del grupo de los llamados científicos, que eran los representantes de la burocracia, terratenientes, comerciantes e intelectuales de más alto rango que se encontraban en la élite del poder, Este hombre, abogado de profesión, fue el director de los periódicos y las revistas más importantes de la época; periódicos como El Universal (1888) o El Imparcial (1896); y la revista El Mundo (1894) la que con el tiempo se convertiría en El Mundo Ilustrado (1900), edición lujosa, en la que se representaba la vida política, económica, social y cultural porfiriana, (Saborit, 2003).

Este emporio de las letras mexicanas, durante la Bella época porfiariana, se encontraba en la Ciudad de México, en la calle De las damas y comunicaba a la calle de Puente Quebrado. Los procesos de producción y distribución se encontraban organizados por departamentos en las mencionadas instalaciones: contaba con un departamento directivo, uno administrativo, uno de redacción y uno de producción (s/a, 1904).

El mundo ilustrado requería de un tratamiento especial por su diseño y calidad, lo que le hizo poseer un departamento separado, con su propio personal y sus propias máquinas. Esta publicación dominical salía de dos prensas planas fabricadas por Walter Scott, con la capacidad de imprimir tres mil ejemplares por hora, los cuales eran encuadernados con máquinas que cosían los pliegos y otras que doblaban las hojas, con capacidad de doblar hasta 3,000 pliegos por hora (s/a, 1904).

Fue así como, con formato de lujo que logró circular durante cerca de veinte años ininterrumpidos, El mundo ilustrado, se convirtió en la revista consentida de la élite porfiriana, ya fuera por ser una emisaria de la modernidad en su propia manufactura, ya fuera por lo encontrado en sus páginas, que semana a semana relataban los eventos más importantes de México, tanto en su cultura como en su sociedad.

En este semanario ilustrado desfilaron un buen cúmulo de fotografías con temáticas diversas, y son el reflejo de los intereses, preocupaciones, gustos y manifestaciones 
de la vida al interior de la clase dominante y el régimen de Díaz; dicha publicación fue su emisaria más fiel y resplandeciente. La revista alardeaba de poseer las más avanzadas técnicas de manufactura y de contener lo más granado de la sociedad mexicana; en otras palabras progreso y civilidad.

En ella la imagen era fundamental, pues para la élite ilustrada que la gestaba y consumía, verse a sí mismos se convirtió en un acto en el que se mostraba su identidad y se educaba para perpetuar ese estado de cosas a los miembros de este grupo de élite, civilizado y moderno.

Por ello, a través de la fotografía se propagaba una serie de valores e ideales que construyen la memoria colectiva de grupo. Es un flujo de recuerdos, evocaciones, costumbres, habitus, que ha orientado la socialización de sus miembros. (Villaseñor, 2011). En una época, donde "...la fotografía no era tan sólo una representación de la realidad, sino que era un objeto que tenía facultades para expresar sentimientos y afectos, [donde] era una prueba irrefutable de las cualidades de las personas y objetos fotografiados." (Matabuena, 1991, p. 8).

Así es como El mundo ilustrado a través de sus páginas muestra estos habitus (Bordieu, 2002) de las clases dominantes, sus ideales y afectos. Hasta ahora, en un ejercicio que apenas comienza, se han podido agrupar algunas de las fotografías que aparecen en la publicación en los siguientes grupos:

a.- Personajes.- De la élite política, económica y social se incluyen retratos y fotografías, de formato pequeño y de la plana completa; de algunos de ellos se muestran retratos individuales, de pareja o de familia; hay casos en que se incluyen fotografías de sus casas tanto en la fachada como en su interior. Por ejemplo se pueden mencionar los retratos del presidente y la primera dama realizados en el estudio de los hermanos Valleto; y los hogares del secretario de hacienda, Jose Yves Limantour, la del empresario Thomas Braniff o la del político y empresario Guillermo de Landa y Escandón.

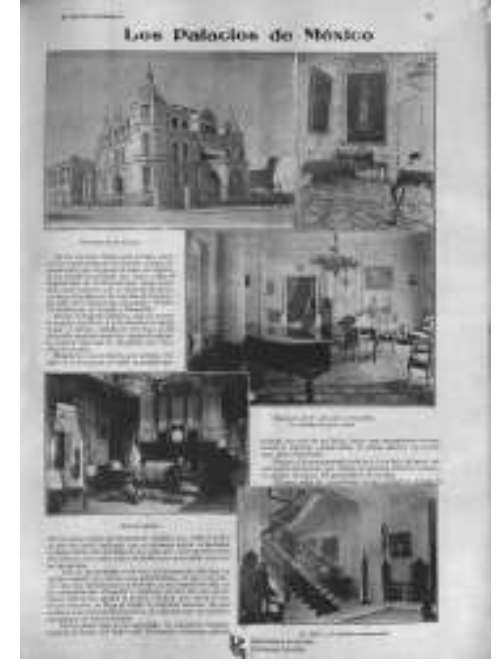

Fotografía 3. Casa de Guillermo de Landa y Escandón, El mundo ilustrado, Ciudad de México, 6 de diciembre de 1908. Biblioteca Armando Olibares Carrillo, Universidad de Guanajuato. Reproducción Ruth Yolanda Atilano Villegas.

b.- Obras públicas.- A lo largo de la publicación se incluyen imágenes sobre la construcción, inauguración y uso de los espacios públicos que se estaban modernizando con el objetivo de asemejar a las grandes capitales del mundo. En estre rubro, son muy sobresalientes las fotografías de la inauguración de la Columna de la Independencia y otros espacios construídos para los festejos del Centenario tan característicos del régimen.

c.-Establecimientos comerciales.- Parte de ese México moderno sin duda alguna era la llegada de los grandes almacenes como el Au Bon Marché parisino, a los cuales les fueron dedicados artículos y fotografías sobre sus espacios, empleados y mercancías; también fueron lucidas un sinfín empresas como la tabacalera y la cervecera. Son muy ilustrativas al respecto las fotografías de tiendas como El Puerto de Liverpool o La gran sedería. 


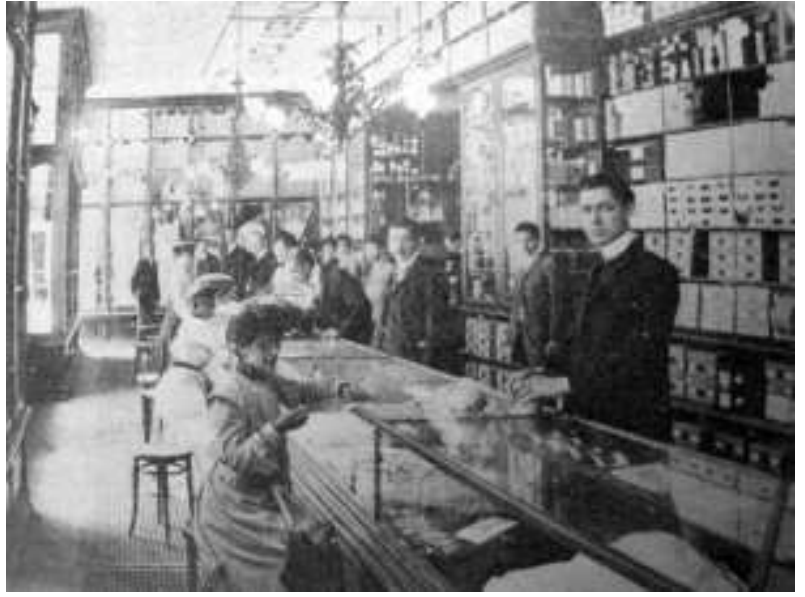

Fotografía 4. La gran sedería, El mundo ilustrado, Ciudad de México, 18 de septiembre de 1904. Colección particular María de la Cruz Labarthe Ríos. Reproducción Ruth Yolanda Atilano Villegas.

d.- Espectáculos.- Esta sección siempre fue muy notable en la revista, en ella se hacían reseñas de los eventos más destacados durante la semana. En ella es posible apreciarse las fotos de diversas funciones teatrales, de cantantes de ópera, de conciertos, o el circo, en foros como el teatro Renacimiento o en espacios públicos.

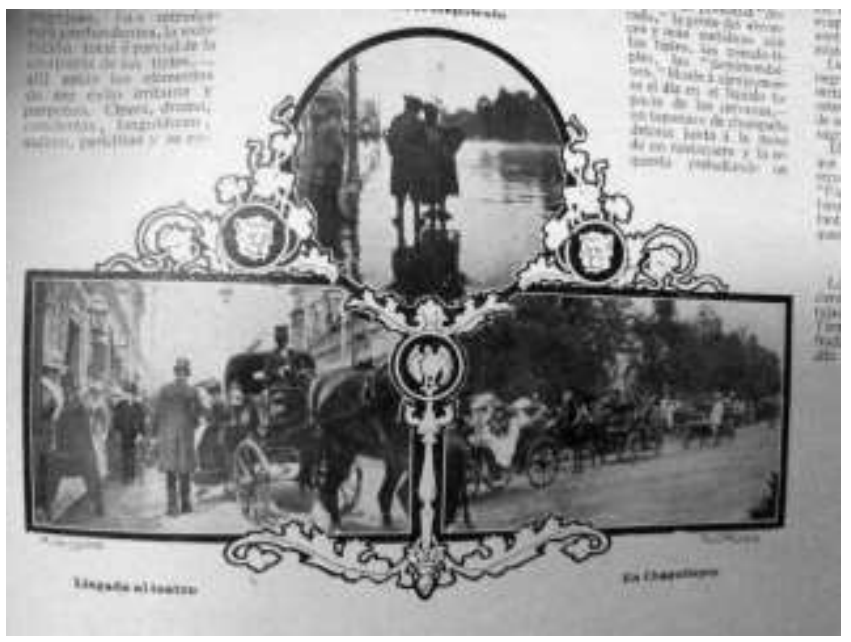

Fotografía 5. La llegada al teatro, El mundo ilustrado, Ciudad de México, 16 de septiembre de 1906. Colección particular María de la Cruz Labarthe Ríos. Reproducción Ruth Yolanda Atilano Villegas.

e.-Eventos deportivos.- Fueron múltiples las ocasiones en que se reseñaron las carreras de caballos, las corridas de toros, el beisbol, o el tenis.
f.-Eventos sociales.- Son tan amplias las temáticas en este sentido; fueron retratadas garden parties, desfiles, kermeses, fiestas de caridad, paseos dominicales, enlaces matrimoniales, entre tantos otros.

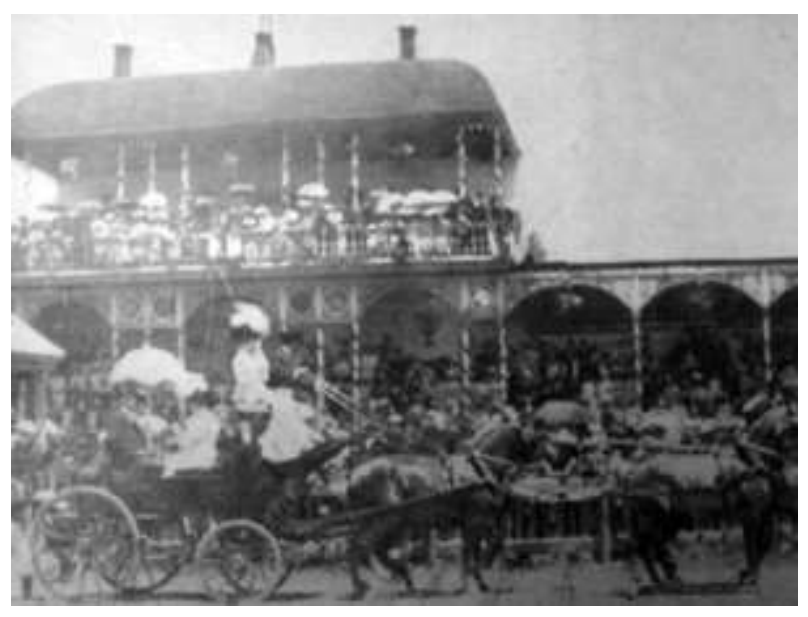

Fotografía 6. Las fiestas francesas, El mundo ilustrado, Ciudad de México, 22 de julio de 1906. Colección particular María de la Cruz Labarthe Ríos. Reproducción Ruth Yolanda Atilano Villegas.

Así mismo, se consignan fotografías y retratos de la realeza, publicitaria, de moda, entre tantas otras. Su observación, organización e interpretación es un trabajo pendiente por hacer. Dichas imágenes, coinciden con la práctica fotográfica en general en el México porfiriano. En estas fotografías, descansaba “... la representación duradera de una persona o cosa, la prueba tangible de su existencia, hombres y objetos [que] quedaron congelados e impresos en las fotos." (Matabuena, 1991, p.8)

\section{Conclusiones}

La prosperidad industrial y económica de México durante el porfiriato, motivó el interés por el registro fotográfico de connacionales y extranjeros, la alta sociedad encontró en el retrato fotográfico, publicado en la prensa ilustrada dirigida para mujeres, al medio ideal para describir su identidad y para promover la instrucción conservadora o liberal de las damas pertenecientes a las élites económicas. El mundo ilustrado, a través de la imagen fotográfica, influyó en los ideales de belleza, de comportamiento moral y en las ideas de modernidad de una minoría privilegiada, que semana a semana observaba con detenimiento las noticias más relevantes en el ámbito nacional e internacional. 


\section{Referencias}

[1] Benítez, Fernando, en Historia de la Ciudad de México, Vol. 6, Ciudad de México, Salvat, p. 80. Citado por Hernández Márquez, Rosario y López rángel, Martha Angélica, Los banquetes del Centenario. El sueño gastronómico del Porfiriato, Ciudad de México, Rosa María Porrúa ediciones, p. 12.

[2] Castillo Troncoso, A. (2005). La fotografía en México, 1890-1920. La diversidad de los usos de la imagen (pags. 59-79). En Garcia Krinsky, Emma Cecilia, coordinadora, Imaginarios y fotografía en México 1839-1970. Barcelona: Lunwerg editores/CONACULTA.

[3] De la Torre Rendón Judith. (1998). Las imágenes fotográficas de la sociedad mexicana en la prensa gráfica del Porfiriato. En Historia Mexicana (343-373). México: El Colegio de Mexico.

[4] Debroise, O. (1985). La producción fotográfica en México. 1839-1899. ¡En La cultura en México - Suplemento de Siempre!, 27 de noviembre de 1985.

[5] García Canclini N. (1978). Uso social y significación ideológica de la fotografía en mexico. En Meyer E., coordinadora, Imagen histórica de la fotografia en México. México: SEP/INHA/FNAS/MNH.

[6] Gómez Tepexicuapan, (1994). Veinte fotógrafos del siglo XIX México: INAH.

[7] Guerrero, Arredondo \& Cruz (2018). La gastronomía mexicana en el porfiriato, en reComiendomexico, México. https://recomiendomexico.wordpress.com/2018/02/16/la-gastronomiamexicana-en-el-porfiriato/ 16 febrero, 2018.

[8] Matabuena Peláez, T. (1991). Algunos usos y conceptos de la fotografía durante el Porfiriato, México: Universidad Iberoamericana.

[9] MODO (2015). Mujeres en el Porfiriato, México: Museo del Objeto del Objeto, https://elmodo.mx/mujeres-en-el-porfiriato/ 22 SEPTIEMBRE, 2015.

[10] Monroy R. (2010). Historia de la fotografía en México, en México Desconocido, México: G21 Comunicación https://www.mexicodesconocido.com.mx/historia-de-la-fotografia-enmexico.html_16-08-2010.

[11] Ortiz Gaitán, J. (2004). Inicios de la fotografía en el discurso publicitario de la prensa ilustrada en Alquimia año 7, núm. 20, enero abril 2004, México: CONACULTA - INHA.

[12] s/a. (1904). "El periodismo moderno", en El mundo ilustrado, Ciudad de México, 3 de enero, año XI, tomo I, número 1.

[13] s/a. (1894-1911). El mundo ilustrado, Ciudad de México: Compañía Editora Mexicana.

[14] Saborit, A. (2003). El mundo ilustrado de Rafael Reyes Spíndola, Ciudad de México: Grupo Carso.

[15] Thorstein, V. (2014). La teoría de la clase ociosa, Madrid, Alianza Editorial.

[16] Villaseñor, E. (2011). Algunas reflexiones en torno a géneros fotográficos, México: Foro Iberoamericano de fotografía, Págs. 1-41. https://mail.google.com/mail/u/0/\#inbox?projector=1 